\title{
Dificuldades do trabalho médico no PSF
}

\section{Difficulties of medical working at the family health program}

Fernanda Gaspar Antonini Vasconcelos ${ }^{1}$

M arilu Ramos Gonçalves Zaniboni ${ }^{2}$

${ }^{1}$ Consultório médico. Rua

Tuity 2009/52, Tatuapé.

03307-000 São Paulo SP.

dra.fevasconcelos@gmail.com

${ }^{2}$ Escola Enfermagem,

UniversidadeBandeirante.

\begin{abstract}
This study aims to identify the profile of doctors who act or acted in PSF, its main difficulties and raisethe percentage of teams of family health without doctor in the city of São Paulo. For this was used a questionnaire based on keywords of the study of Capozzolo collected from January to M ay 2008, and data of the Primary Care from October until December 2007. The main results include a time less than 5 years of training for most of the interviewees and affinity by the PSF as motivation for work. Some of the main difficulties are the high demand, high incidence of complex cases, difficulty of listings, profile division of time is not consistent with health needs and lack of incentive to specialization. The figures for Primary Care demonstrated that the coordination East had the highest absence of experienced doctors in the period analyzed, with rates around 20 to $40 \%$, the existence of an increase in the deficit as the end of the year gets closeand themaintenance of deficits in someunits. Key words Family Health Program, Public health, Primary health care
\end{abstract}

Resumo 0 presente estudo tem como objetivos identificar o perfil dos médicos que atuam ou atuaram no PSF, suas principais dificuldades e levantar a porcentagem de equipes de saúde da família sem médico no município de São Paulo. Para isso, foi utilizado um questionário baseado nas principaisfalas do estudo de Capozzolo, coletadas dejaneiro até maio de 2008, e dados da atenção básica de outubro até dezembro de 2007. Os principais resultados incluem um tempo menor que cinco anos de formação para a maioria dos entrevistados e afinidade pelo PSF como motivação para o trabalho. As principais dificuldades referem-se à alta demanda, alta incidência de casos complexos, dificuldade de referenciamento, perfil de divisão do tempo não condizente com as necessidades de saúde e falta de incentivo à especialização. 0 s dados da atenção básica demonstraram que a Coordenadoria Leste foi a que mais sofreu falta de mé dicos no período analisado, mantendo índices em torno de $20 \%$ e $40 \%$; existência de um aumento no déficit com a aproximação do final do ano e a manutenção dos déficits em algumas unidades. Palavras-chave Programa de Saúde da Família, Saúde pública, Atenção básica 


\section{Introdução}

Em 1966, nos Estados Unidos, surge a medicina de família, como um movimento de reforma médica para responder aosimpasses do alto custo e superespecialização da assi stência médica.

Esse movimento espalha-se para a América Latina e é introduzido no Brasil em 1973 através da Organização Mundial de Saúde (OM S) e Associação Brasileira de Ensino M édico (ABEM). Até esse momento, no Brasil, o direito à saúde era exclusivo aos inseridos no mercado de trabaIho, a chamada cidadania regulada; a assistência individual e curativa ficava a cargo da Previdência Social, enquanto que os cuidados preventivos e coleti vos ficavam a cargo do M inistério da Saúde e secretárias de saúde, sendo realizados através de programas específicos elimitados. A baixa resolutividade da assistência, a grande exclusão de parte da população e a crise financei ra levam à eclosão da Reforma Sanitária.

0 projeto da Reforma Sanitária é aprovado na Constituição de 1988 e inova com o conceito de direito à saúde para todos e a criação do SistemaÚ nico deSaúde, tendo como diretrizes a universalidade, integralidade e participação social ${ }^{1-}$ 3. Em 1994, é criado o Programa de Saúde da Família como uma estratégia da atenção básica, reorientando o modelo assistencial com a implantação de equipes multiprofissionais em Unidades Básicas de Saúde ${ }^{4,5}$.

o financiamento do novo modelo assistencial deixa de ser baseado em procedimentos para ser per capita, o queé denominado de piso fixo de atenção básica (PAB), eédirecionado do M inisté rio da Saúde para os municípios. Além disso, a NOB 96 garanteo piso de atenção básica variável, queédirecionado conformeações realizadas pelo município, como o Programa de Saúde da Família6. Propõe-se também a separação de ações de financiamento e execução de serviços através das organizações sociais (OS), modelo jurídico de organizações públicas não estatais de direito privado, para gerir complexos equipamentos públicos, como hospitais, universidades, entre outros. As OS tem o direito, entre outras coisas, de contratar pessoal sem concurso público, adotar normas próprias para compras e contratos, adotar orçamentos regrados por contratos de gestão, etc. ${ }^{1}$. Exemplos deOS no município de São Paulo são a Associação Comunitária M onteAzul, SPDM (Associação Paulista para o Desenvolvimento da M edicina) eSanta M arcelina.

Com a reforma, as Unidades Básicas de Saúde passaram a ser muito mais do que porta de entrada do sistema de saúde, servindo de local essencial para a realização da integralidade das ações individuais e coletivas de saúde, além da linha de contato entre as práticas de saúde e as práticas sociais que determinam a qualidade de vida da populaçãa ${ }^{1,7}$.

O Programa de Saúde da Família atua através de equipes mínimas formadas por médico, enfermeiro, auxiliar de enfermagem eagentes comunitários de saúde, enquanto que a ampliada conta ainda com dentista, auxiliar de consultório dentário e técnico em higiene dental. Essas equipes são responsáveis por ações de promoção, prevenção, recuperação, reabilitação dos agravos e doenças mais frequentes na comunidade, uma responsabilidadeque abrangeo acompanhamento de aproximadamente três a 4.500 pessoas ${ }^{5}$.

0 médico tem papel fundamental no Programa de Saúde da Família, seja na avaliação da demanda do paciente, dos riscos individuais do adoecer, como na elaboração de um projeto terapêutico para responder àsnecessidades deatenção, desde prevenção até reabilitação. Além disso, tem que incorporar no seu atendimento individual aspectos referentes ao emocional, ao familiar, ao social eà prevenção. Junto com as ações de assistência, o médico deve realizar ações educativas, coletivas e comunitárias em conjunto com os demais profissionais da equipe, bem como participar do planejamento e organização do processo de trabalho. 0 programa estipula como atividades semanais dos médicos 0 atendimento de consultas naunidade, atividades educativas de grupo, reuniões de equipe e atendimento domiciliar, compreendido como importante para a aproximação dos profissionais com a realidade do local onde vivem as famílias, e ainda estipula instrumentos que permitem avaliar a cobertura da população e a produç̧ão dos profissionais ${ }^{1}$.

O programa como estratégia da atenção básica tem atualmente uma cobertura populacional em torno de $46,2 \%$, que corresponde a 85,7 milhões de pessoas, segundo dados do M inistério da Saúde. No município de São Paulo, essa cobertura é de $25,02 \%$.

A grande cobertura populacional, junto as suas importantes funções para com a saúde da população em geral, torna o programa o "carrochefe da atenção básica em saúde". É nesse enfoque que discutiremos nesse estudo al gumas dificuldades encontradas para a atuação eficaz do mesmo: a dificuldade de contratação do profissional médico para atuação nas equipes, sua manutenção e dedicação ao programa. 


\section{Objetivos}

0 estudo tem como objetivos identificar o perfil dos médicos que atuam ou atuaram no programa; identificar as principais dificuldades enfrentadas por esses profissionais; ressaltar a importância desse profissional no programa elevantar a porcentagem de equipes sem esse profissional no município de São Paulo.

\section{M ateriais emétodos}

0 perfil dos profissionais e suas principais dificuldades foram levantados através de questionário aplicado a médicos que atuam ou atuaram no Programa de Saúde da Família no município de São Paulo, após esclarecimento dos objetivos do estudo epreenchimento do termo de consentimento livre e esclarecido. 0 período da coleta foi de fevereiro de 2008 atémaio do mesmo ano.

A importância do profissional médico foi levantada através de uma única pergunta - "O que você acha da função do médico no programa? com as possíveis respostas: muito importante, essencial; importante, não essencial; não importante, feita aos profissionais não médicos que atuam ou atuaram no programa e população coberta pelo programa, após preenchimento do termo de consentimento livreesclarecido. A atenção básica forneceu os dados sobre o déficit de médicos nos meses de outubro, novembro e dezembro de 2007.

\section{Resultados}

Foram coletadas 54 entrevistas médicas, sendo que 32 foram conseguidas durante 0 Congresso deSaúde da Família e 22 de médicos atuantes em unidades de PSF (Programa Saúde da Família) fora do congresso. A coleta dos dados ocorreu de fevereiro a maio de 2008. Foram coletadas 44 entrevistas de profissionais não médicos.

Resultados dos questionários

Perfil dos médicos

D os 54 entrevistados, 48 estavam atuando no Programa de Saúde da Família, vinculados ou não à residência médica, quatro não citaram e dois não estão atuando. 22,2\% dos médicos entrevistados disseram ser recém-formados.

Ressalta-se que quase metade dos entrevistados (48\%) não respondeu a essa pergunta. 39\% tinham menos de cinco anos de formação, $4 \%$, de cinco a dez anos e $9 \%$, mais de dez anos.

Somente quinze responderam ao item outro trabalho; desses, somente três assinalaram positivamente.

No Gráfico 1, os motivos pelo quais os profissionais atuam ou atuaram no PSF. Consideramos nessa questão 59 respostas, pois alguns entrevistados responderam mais de um item. 55,5\% dos médicos referiram alguma experiência anterior, seja ela U BS tradicional ou PSF.

Avaliação do trabalho no programa

A resposta da relação detrabal ho com a equipe de saúde da família foi praticamente unânime: $96,1 \%$ dos entrevistados afirmaram que a relação é harmoniosa, somente dois caracterizaram como difícil e dois entrevistados responderam o item regular não registrado no questionário e, por isso, foram descartados.

$74 \%$ dos entrevistados marcaram pouco na questão tempo destinado às consultas individuais, somente um entrevistado marcou tempo excessivo. $65 \%$ dos entrevistados apontaram que o tempo destinado às atividades coletivas é pouco.

0 perfil da divisão de tempo entre consultas individuais eatividades coletivas foi considerado não condizente com as necessidades da área de abrangência para 70,3\% dos médicos. Em contrapartida, 53,8\% consideraram não condizente com as diretrizes do Programa Saúde da Família

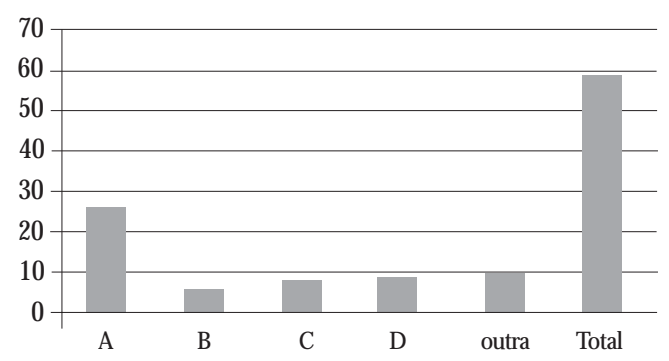

M otivação para atuação no PSF

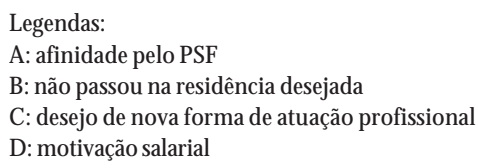

Gráfico 1. M otivos pelo quais os profissionais atuam ou atuaram no PSF. 
(PSF). 0 vínculo com as famílias foi considerado importante para a condução dos casos para $71,6 \%$ (38), mas $28,3 \%$ consideraram importante, porém desgastante.

Para $64 \%$ dos entrevistados, a carga horária dequarenta horas éadequada, $36 \%$ consideramna excessiva. 92,5\% dos médicos assinalaram que a demanda da área de abrangência é alta.

No Gráfico 2, o ponto de vista dos médicos que atuam no PSF sobre a incidência de casos complexos, entendidos aqui como os casos que não seriam de responsabilidade das UBS.

$87 \%$ dos entrevistados referiram incidência alta ou moderada de casos complexos.

No Gráfico 3, a retaguarda dos casos complexos sob o ponto de vista dos entrevistados.

$83 \%$ dos entrevistados negaram a existência de incentivo ou facilidades de especialização na área de atuação; em contrapartida, 83\% têm interesse de especialização na área.

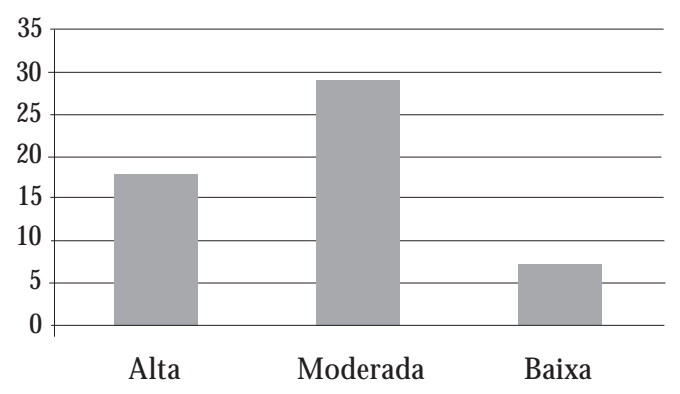

Gráfico 2. Incidência casos complexos sob o ponto de vista dos médicos que atuam no PSF.

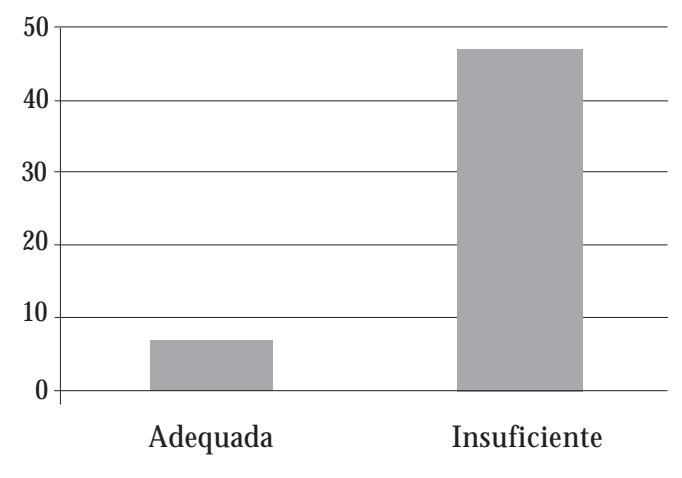

Gráfico 3. Retaguarda dos casos complexos sob o ponto de vista dos médicos entrevistados.
No Gráfico 4, a avaliação salarial dos médicos no PSF, segundo médicos entrevistados.

$93 \%$ dos 44 profissionais não médicos consideram a função do médico essencial. 0 espaço destinado às considerações foi preenchido basicamente com os lembretes de que todos os profissionais são importantes na equipe (Gráfico 5).

\section{Discussão}

É importante relatar que $22,2 \%$ dos médicos são recém-formados e $75 \%$ dos que citaram tempo de formação têm menos decinco anos de formação, evidenciando que devemos incentivar o co-

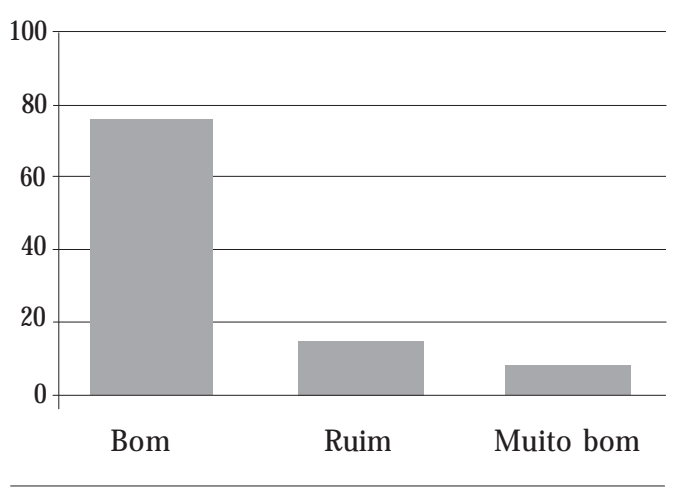

Gráfico 4. Avaliação salarial dos médicos no PSF, segundo médicos entrevistados.

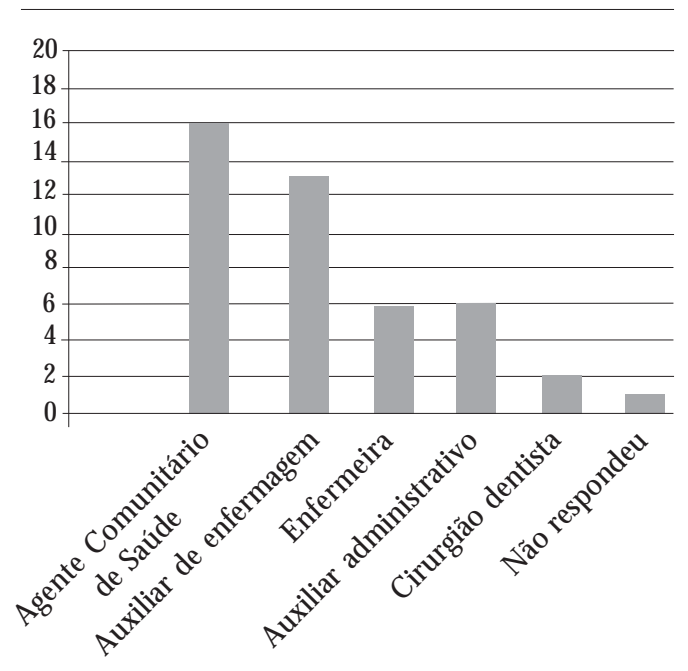

Gráfico 5. Função dos profissionais não médicos entrevistados. 
nhecimento da medicina de família ecomunidade nas faculdades e as especializações e atualizações contínuas.

Para benefício da medicina defamília ecomunidade, $44 \%$ dos médicos referem afinidade pelo programa, mas é alta a porcentagem de médicos que citam também a motivação salarial e a dificuldade de ingresso nas residências médicas, totalizando 25,2\% dos entrevistados, o que evidencia que os profissionais realmente vinculados às diretrizes do programa não são muitos e deveriam, de alguma forma, ser valorizados. Ressalta-se aqui que 32 dos 54 entrevistados estavam no Congresso de Saúde da Família e Comunidade e, portanto, teriam al guma vinculação com o programa. Separando as duas categorias de entrevistados em participantes do congresso ou atuantes em UBS com PSF, temos que a primeira respondeu afinidade em $58,8 \%$, enquanto que a segunda, em $24 \%$. Para motivação salarial eo não ingresso na residência médica, a primeira participou com $3 \%$, enquanto que a segunda, com $56 \%$. Osmédicos atuantes sem vinculação com especializações ou residência médica tran fformam o programa em oportunidades de trabalho.

$45 \%$ dos médicos não têm experiências anteriores em UBS tradicionais ou no programa, levantando a necessidade de especializações e atualizações na área.

50 dos 52 médicos referiram que a relação com a equipe é harmoniosa, resultado satisfatório, já que o trabalho do programa é dependente de todos os membros da equipe. Dois dos entrevistados inseriram a resposta regular e não foram computados.

Como lembrado no estudo de Matumoto et al. ${ }^{8}$, o trabalho em equipe na prática apresenta dificuldades de ordem técnicae, principalmente, interpessoal, obstáculos epistemológicos (do campo do conhecimento) e epistemofílicos (do sentimento esubjetividade). 0 mesmo estudo cita a influência das demandas sobre as relações das equipes, gerando ansiedade e angústias nos trabalhadores, tanto pela demanda reprimida quanto por seu conteúdo (pobreza).

$74 \%$ dos entrevistados acham pouco o tempo destinado às consultas individuais. Levantamos aqui um dilema: será que os médicos estão insatisfeitos com o tempo destinado às consultas individuais por não serem condizentes com as necessidades da área ou será que os mesmos continuam com o enfoqueassistencial individual e, por isso, acham o tempo inadequado? Uma situação que chama atenção é que, dos 22 entrevistados fora do Congresso, treze (59\%) relataram tempo adequado às consultasindividuais, completamente diferente da outra categoria de entrevistados, em que todos declararam pouco tempo.

Com relação ao tempo destinado às atividades coletivas, a situação é diferente: $35 \%$ dos entrevistados declaram adequado e $65 \%$, pouco, mostrando que os médicos têm consciência da importância dessas atividades, mas, por algum motivo, não destinam tempo adequado a essa atividade. 0 perfil da divisão detempo entreconsultas indi viduais eatividades coletivas foi considerado não condizente com as necessidades da área de abrangência para 70,3\% dos médicos; em contrapartida, 53,8\% consideraram não condizente com as necessidades do Programa Saúde da Família (PSF). Os dados sugerem que o profissional tem se preocupado mais com as diretrizes do programa do que com as reais necessidades da população de sua área de abrangência. Essa constatação faz pensar quetal vez não sefaça planejamento estratégico e que, por vezes, as necessidades da população não estão restritas às diretrizes do programa.

Todos os médicos acreditam que o vínculo com as famílias é importante na condução dos casos; porém, não é inexpressiva a parcela que a considera também desgastante, levantando a necessidade de diminuir, de alguma forma, 0 desgaste desse profissional.

A maioria dos médicos considera a carga horária adequada, não representando esse um motivo importante para a falta desse profissional.

87\% referiram incidência alta ou moderada de casos complexos. É quase unânime a declaração de que a demanda da área e a incidência de casos complexos sem referência adequada são altas, evidenciando um grande motivo para possível insatisfação do profissional.

A falta deincentivo ou facilidade de especialização foi levantada de forma incisiva, anunciando uma insatisfação; $81,4 \%$ dos entrevistados têm interesse de especialização na área.

O salário não foi considerado um problema, já que 46 dos 54 médicos o consideram bom.

$93 \%$ dos profissionais não médicos consideram a função do médico essencial, reforçando a importância do médico no programa. Muitos profissionais complementaram a resposta reforçando que todos os profissionais são essenciais, mostrando a visão do trabalho em equipe, em quenenhuma parteémenos ou mais importante.

Com relação aos dados da atenção básica, a Coordenadoria Leste apresentou o maior déficit de médicos nos meses estudados (outubro, novembro e dezembro). 
Das 27 supervisões, catorzetiveram déficit de médicos aumentado de outubro para dezembro; esse fato pode ser explicado pelo fato dos médicos saírem do trabalho para se preparar para a prova de residência médica que ocorre no final do ano e começo do seguinte.

Dez das 27 supervisões apresentaram um déficit de médicos acima de $20 \%$ na média do período analisado. Uma única observação fica na supervisão da Penha, onde o déficit em outubro ficou abaixo de $20 \%$, mas foi considerada, pois nos meses seguintes apresentou um déficit el evadíssimo de 37,5\%.

Podemos observar também que as supervisões que apresentaram déficits el evados tendem a mantê-los durante o período, o que sugere que essas regiões permanecem sem médicos por um período prolongado.

Em recente apresentação no I Encontro de Ligas Acadêmicas de M edicina de Família e Comunidade, resumido na Revista Brasileira de M edicina de Família e Comunidade, alguns pontos de interesse desse estudo foram levantados. 0 primeiro deles expõe a dificuldade em conciliar o curso médico com as atividades extracurriculares, o que impossibilita a vivência do aluno e, consequentemente, o conhecimento de atuações relativamente novas como a medicina de família e comunidade; 0 enfoque terciário da faculdade de medicina, hospitalocêntrico, dificultando 0 surgimento do gosto pela atenção primária; a participação maior de alunos de enfermagem na Liga, mostrando o

desinteresse dos estudantes de medicina pela área?. Alguns avanços ocorreram no sentido de melhorar a percepção dos estudantes sobre o perfil do médico exigido na medicina de família e comunidade; as novas diretrizes para o ensino médico, instituídas em 2001, preconizam a formação do médico generalista, humanista, crítico ereflexivo, capacitado a atuar, pautado em princípios éticos, no processo saúde-doença, em seus diferentes níveis de atenção, como ações de promoção, pre venção, recuperação ereabilitação à saúde, na perspectiva da integralidade da assistência, com senso de responsabilidade social e compromisso com a cidadania, como promotor da saúde integral do ser humano. No entanto, como exposto pelas ligas no parágrafo acima, o enfoque hospitalocêntrico ainda é mantido nas faculdades ${ }^{10}$.

Um outro avanço foi a inserção dos acadêmicos na comunidade já no início do curso, possibilitando o contato com as pessoas no seu contexto familiar e comunitário, mas isso não ocorre em todas faculdades ${ }^{11}$.
Santos ${ }^{11}$ ressalta pontos positivos e negativos do trabalho no programa. Entre os positivos, estão uma melhor cobertura assistencial da população e 0 acréscimo salarial importante; entre os negativos, a falta de desenvolvimento do atendimento especializado e da atenção hospitalar, gerando demanda reprimida e dificuldade de encaminhamentos dos problemas que não podem ser resolvidosno nível primário; dificuldadedo trabaIho multiprofissional gerada principalmente pela deficiência da formação acadêmica, também pela falta de perfil exigido e trabal ho em período integral, gerando ações individuais dos profissionais verdadeiramente engajados; a ênfase à especialização, prejudicando a humanização da atuação profissional ea população estar acostumada com 0 antigo sistema assistencial, tendo dificuldadeem absorver novas práticas. Através de entrevistas com médicos, enfermeiras e agentes comunitários de saúde, Pedrosa et al. ${ }^{12}$ enfatizam que as relações da equipe com a comunidade vinculam-se à busca de consulta médica e medicamentos.

A necessidade de um processo de capacitação contínua e eficaz das equipes, muitas vezes deixada de lado devido à grande demanda eà necessidade de se cumprir as metas exigidas.

A grande demanda, a existência de salários mais elevados em outros locais, a resistência da comunidade, a dificuldade de referência e contrarreferência, a difícil relação com os outros membros da equipe e principalmente a desvalorização do profissional do programa por outros médicos tornam o trabalho médico no desgastante ${ }^{13}$. De forma resumida, expomos na Tabela 1 as justificativas plausíveis para o déficit de médicos.

Ressaltamos nesse estudo a necessidade de capacitação contínua dos médicos que atuam no programa, por vezes submetidos a demandas variadas sem referências adequadas. Contudo, os médicos de família têm sua capacitação não fornecida e até dificultada, por causa de alguns parceiros que exigem tempo de trabalho no programa para liberação ou mesmo não permitem cursos de especialização na área. Pou cos já são os médicos quequerem seespecializar, menor ainda o número daqueles que conseguem.

0 médico defamília ecomunidadeéarrebatado por problemas desaúde variados, muitas vezes resultado do meio social, sem grandes possibilidades de mudança, já que dependem de mudanças em outras esferas como educação, economia, saneamento, etc., mas que tem a unidade como única porta deentrada. Sem referência adequada e retaguarda apropriada, vê-se a única possibilidade de resolução dos problemas da sua comunida- 
Tabela 1. Justificativas plausíveis para o déficit de médicos.

\begin{tabular}{ll}
\hline \multicolumn{1}{c}{ Anterior a formação } & \multicolumn{1}{c}{ Durante a atuação no Programa } \\
\hline Falta de vivência em Medicina de Família & Dificuldade de encaminhar (referência e contra) \\
Enfoque hospitalocêntrico das faculdades & Dificuldade na retaguarda hospitalar \\
Desinteresse do acadêmico & Dificuldade na relação com outros profissionais \\
& Período integral de trabalho \\
& Ênfase à especialização e desvalorização profissional pelos \\
& próprios colegas \\
& Falta de entendimento da população sobre o programa \\
& Grande demanda \\
& M elhores possibilidades salariais \\
\hline
\end{tabular}

de, muitas vezes tendo que tratar casos que não seriam da atenção primária, zela por pessoas que não sabem ao certo a função e os limites desse profissional, ficando ele, ea equipe, como um todo, de escudo frente a qualquer reclamação em saúde. Por tudo isso, esse profissional sofre desgastes físicos e psicológicos importantes, necessitando de melhores condições de trabalho, salariais e não salariais, além de capacitação contínua.

Pretende-se também com esse estudo discutir as exigências para aquisição do título de especialista em medicina de família e comunidade Em 2007, eram exigidos 36 meses consecutivos ou não de atuação na área ou conclusão de residência médica em medicina de família ecomunidade. Atualmente, são exigidos 48 meses de atuação. Essa mudança pode ser interpretada como importante para qualificação profissional ou mais uma dificuldade a ser enfrentada por esse profissional. Talvez a dificuldade de aquisição e manutenção dos médicos no programa pudesse ser atenuada pelas facilidades de especialização eaquisição detítulos.

M asnem tudo são dificuldades; o médico que atua no programa provavelmente, dentre todas as especialidades, é 0 que sente mais de perto a gratidão das pessoas frente ao seu trabalho e 0 que mais percebe o resultado biológico e psicológico de uma boa relação médico-paciente. 0 vínculo criado com os pacientes e o trabalho em equipe pode ser capaz de gerar uma grande família e trazer muitas gratificações.

As filas no SUS são em parte devido à falta de médicos nas U $B S$, ao excesso de pessoas de responsabilidade das equipes de saúde da família, à dificuldade de referenciar os pacientes, desconhecimento da população sobre qual serviço procurar. Na verdade, o que se observa hoje no sistema de saúdeéum vai vém de pacientes sem destino certo, procuram as UBS, são referenciados para os AM AS, recebem atendimento emergencial, voltam para as UBS, são referenciados para os hospitais ou centros de especialidades, que os referencia para as UBS, etc.

\section{Considerações finais}

O estudo evidenciou pontos positivos, ou seja, não considerados empecilhos à prática do PSF, $\mathrm{e}$ pontos negativos.

Entreos pontos positivos estão afinidade pelo programa, relação harmoniosa com a equipe, vínculo com a população, carga horária adequada e salário adequado.

Os pontos negativos destacados são pouco tempo destinado às atividades individuais ecoletivas, perfil de divisão não condizente com as necessidades da área, tampouco com as prioridades do programa, alta demanda, alta incidência de casos complexos, referências inadequadas efalta de incentivo à especialização.

Os médicos atuantes no PSF entrevistados fora do congresso, em comparação com esse grupo, têm pouca vinculação com o programa e 0 não ingresso na residência médica parece ser a grande motivação para o trabal ho.

Em resumo, devemos valorizar os médicos realmente vinculados com as diretrizes do programa, incentivando especializações e educação continuada. 


\section{Colaboradores}

FGA Vasconcelos trabalhou na concepção teórica, elaboração e redação final do texto; M RG Zaniboni trabalhou na coleta de dados e elaboração do texto.

\section{Referências}

1. Capozzolo AA. No olho do furacão. Trabalho médico e o Programa de Saúde da Família [tese]. Campinas (SP): Unicamp; 2003.

2. Paim JS. A Reforma Sanitária e a M unicipalização. Revista Saúde e Sociedade 1992; 1(2):29-47.

3. Bertolozzi MR, Greco RM. As políticas de saúde no Brasil: reconstrução histórica e perspectivas atuais. Rev. Esc. USP 1996; 30:380-398.

4. Silveira RP, Dohms MC. A Medicina de Família e Comunidade e o ensino de graduação em Medicina. M etodologias ativas de Ensino/Aprendizagem. Rev Bras M ed Fam Com 2007; Supl. 1:21-25.

5. Brasil. Ministério da Saúde. Saúde da Família. [site da Internet]. [acessado 2007 dez]. Disponível em: http://www.saude.gov.br/saúdedafamília

6. Aretche M. Financiamento Federal e gestão local de políticas sociais: 0 difícil equilíbrio entre regulação, responsabilidade e autonomia. Cien Saude Colet 2003; 8(2):31-345.

7. Merhy EE. A rede básica como construção da Saúde Pública e seus dilemas. In: M erhy EE, Onocko $\mathrm{R}$, organizadores. Agir em Saúde. Um desafio para 0 público. São Paulo: Hucitec; 1997. p. 197-228.

8. M atumoto $S$, Fortuna $C M, M$ ishima SM, Pereira MJB, Domingos NAM. Supervisão de equipes PSF: reflexões acerca do desafio da produção de cuidados. Interface (Botucatu) 2004-2005; 9(16):9-24.

9. Oliveira AM F, Brunelli B, Kanno NP, Lora PST. Apresentação do I Encontro de Ligas Acadêmicas de Medicina de Família e Comunidade. Rev Bras Med Fam Com 2006; Supl. 1:11-15.

10. Brasil. M inistério da Educação. Conselho Nacional de Educação. Parecer 1.133.01. Institui Diretrizes Curriculares do curso de graduação em M edicina. Diário Oficial da União 2001; 3 out.

11. Santos MAM. A interdisciplinaridade e o trabalho em equipe no PSF. ACM arq catarin méd 2004; 33(3):31-40.

12. Pedrosa JL, Teles JBM. Consensos e diferenças em equipes de saúde da família. Rev. Saude Publica 2001; 35(3):303-311.

Artigo apresentado em 23/05/2008

Aprovado em 31/10/2008

Versão final apresentada em 08/01/2009 